DARIUSZ GOTLIB, JACEK MARCINIAK

Warsaw University of Technology

\title{
CARTOGRAPHICAL ASPECTS IN THE DESIGN OF INDOOR NAVIGATION SYSTEMS
}

\begin{abstract}
The development of indoor navigation systems should utilize advanced teleinformation, geoinformation and cartographical knowledge. The authors analyzed available specifications of prototypes of indoor navigation systems and drew conclusions about how to enhance the use of cartographical methods in the whole process of designing a new system. The analysis proves that cartographical methodology is still very limited in the process of designing indoor navigation systems. Researchers focus mainly on improving the positioning accuracy, and they often neglect the issue of developing spatial databases and the rules of their effective visualization. The process of designing indoor navigation systems, just like in the case of outdoor navigation systems, consists of a number of tasks that can be supported by the theory and practice of cartography. This article presents the issues of determination of spatial database model appropriate for an indoor system, improvement of accuracy of positioning algorithms utilizing spatial data and methodology of generating graphical and voice directions for indoor navigation. In the authors' opinion, the discussed cartographical methods and techniques may considerably enhance indoor navigation systems and accelerate their development. The fundamental knowledge of cartographical methods should be within the interest of designers of these systems. At present the first attempts in this field may be observed, although they are still not mature and complex.
\end{abstract}

\section{Keywords:}

mobile cartography, building modeling, indoor navigation, GIS, LBS.

\section{INTRODUCTION}

Mobile applications, including Location-Based Services (LBS) and navigation systems for cars, bicycles, pedestrians as well as air and marine navigation systems have recently been widely popularized. These services utilize Global Navigation Satellite Systems (GNSS) to track the position of a user. As the GNSS signal is too weak indoors in order to provide navigation inside buildings, there are attempts to use other positioning technologies based on radio infrastructure (WiFi, RFID ${ }^{1}$ tags, Bluetooth, $\mathrm{UWB}^{2}$ ), ultrasounds,

\footnotetext{
${ }^{1}$ RFID - Radio Frequency Identification.

${ }^{2}$ UWB - Ultra WideBand, technology based on sending ultrashort pulses.
} 
vision systems, dead reckoning and other experimental approaches. In the near future it will be possible to locate a user inside shopping malls, in underground parking areas, hotels, hospitals, office buildings, etc. It will also be possible to navigate a user to a shelf with specific goods and provide personalized advertisements or send promotional coupons (mobile marketing). In case of emergency, the user will be updated with evacuation routes from their current location.

In order to provide reliable navigation, an appropriate spatial database is required in the form of an indoor map with additional data. The development of indoor navigation systems utilizes advanced teleinformation, geoinformation and cartographical knowledge. The authors analyzed available specifications of prototypes of indoor navigation systems and drew conclusions about how to enhance the use of cartographical methods in the whole process of designing a new system.

\section{INDOOR POSITIONING SYSTEMS}

This paper presents selected indoor navigation systems of various characteristics and of diversified market maturity. Most attention is paid to complete solutions, which have been officially presented by their manufacturers and which are able to become commonly accessible market products. The following solutions were tested: Google Maps (Google), Ovi Maps (Nokia), Mobile Explorer Platform (Loctronix), 'Copernicus Science Center Guide' (Samsung) and a prototype made by the University of Cagliari. The majority of technical information originates from scientific publications, press releases, publicly available tests and users' opinions presented in the Internet fora. Due to the lack of physical access to applications, conclusions presented in this paper should be considered only as preliminary opinions.

In November 2011 Google Maps 6.0 was launched with support for indoor navigation [5]. This product allows the users to create a plan of the building interior on their own and to make that plan available on the Internet. This solution allows for the development of maps of building interiors all over the world, similarly to 3D models of objects in Google Earth. The Google Company operates as the distributor of a popular map platform and at the moment it does not focus on the development of complex positioning algorithms. The tested version utilizes basic positioning based on GPS, mobile networks and WiFi Access Points. The Company delivers advanced programming components, allowing the users to develop their own, local solutions using the Google Maps platform for spatial reference.

The Nokia Company applied in Ovi Maps a solution which allows obtaining high positioning accuracy using directional antennas installed inside buildings. This solution is based on the AoA (Angle of Arrival) method and it utilizes an extension 
of the Bluetooth $4.0^{3}$ protocol. During the Nokia World 2010 conference in London, the manufacturer estimated the positioning accuracy as better than $0.5 \mathrm{~m} \mathrm{[3].} \mathrm{The}$ Ovi Maps application integrates an outdoor navigation system based on GNSS with an indoor solution, providing automatic switching of the operating mode when the user enters a building with installed positioning infrastructure. Such an approach implements the idea of seamless navigation that adjusts itself to the spatial context. At this stage though, it is not yet a ubiquitous service, since the accessibility of the system is still limited to several buildings (mainly airports in Finland).

Another supplier of outdoor/indoor positioning solutions is the Loctronix Company. The Mobile Explorer Platform ${ }^{\mathrm{TM}}$ (MEP) technology, developed by this company, is based on the patented technology of Spectral Compression Positioning (SCP). The solution provides the position with an accuracy of 1 meter using the commonly available radio signals: GNSS, mobile networks and WiFi, supported by a dedicated SCP beacon [1].

Table 1. Basic features of tested indoor navigation applications [own study]

\begin{tabular}{|l|c|c|c|c|c|}
\hline $\begin{array}{l}\text { Positioning } \\
\text { method }\end{array}$ & $\begin{array}{c}\text { GiFi, mobile } \\
\text { telephone } \\
\text { networks, GPS }\end{array}$ & Bluetooth AoA & $\begin{array}{c}\text { WiFi } \\
\text { Fingerprinting }\end{array}$ & $\begin{array}{c}\text { RF } \\
\text { Fingerprinting } \\
\text { and Doppler }\end{array}$ & Dead reckoning \\
\hline $\begin{array}{l}\text { Additional } \\
\text { infrastructure }\end{array}$ & N/A & $\begin{array}{c}\text { Directional } \\
\text { antennas }\end{array}$ & N/A & SCP beacon & $\begin{array}{c}\text { QR Code } \\
\text { indexes }\end{array}$ \\
\hline $\begin{array}{l}\text { Typical } \\
\text { accuracy }\end{array}$ & $10-15 \mathrm{~m}$ & $0,3-0,5 \mathrm{~m}$ & $5-10 \mathrm{~m}$ & $1 \mathrm{~m}$ & $10 \mathrm{~m}$ \\
\hline Maturity & Market solution & Market solution & Market solution & Market solution & Prototype \\
\hline $\begin{array}{l}\text { Routing and } \\
\text { navigation }\end{array}$ & Outdoor & Indoor & N/A & N/A & N/A \\
\hline Coverage & Global & Global & 1 building & $\begin{array}{c}\text { Component; } \\
\text { solution } \\
\text { dependent }\end{array}$ & 1 building \\
\hline $\begin{array}{l}\text { Current } \\
\text { availability }\end{array}$ & $\begin{array}{c}\text { IKEA shops } \\
\text { and airports } \\
\text { in the US }\end{array}$ & $\begin{array}{c}\text { Airports in } \\
\text { Finland }\end{array}$ & $\begin{array}{c}\text { Copernicus } \\
\text { Science Center } \\
\text { in Poland }\end{array}$ & N/A & $\begin{array}{c}\text { N/A } \\
\text { (prototype) }\end{array}$ \\
\hline
\end{tabular}

Apart from solutions designed for many places, applications for navigation in selected buildings are also developed. An example of such a solution is the 'Copernicus Science Center Guide ${ }^{4}$, issued by Samsung Electronics in April 2012. The application aggregates general information for visitors and navigates them around

\footnotetext{
${ }^{3}$ Nokia expects to introduce a protocol extension to the Bluetooth standard in 2013.

${ }^{4}$ Copernicus Science Center is an interactive science center established in 2005 in Warsaw.
} 
the site. Positioning is performed using WiFi signal based methods combined with readouts from inertial sensors. As a result of such an approach, the application operates on every mobile phone with the Android system.

Besides commercial solutions, a number of applications are developed for research purposes. One of them is a prototype presented in 2010 by researchers from the GeoWeb Laboratory, University of Cagliari and CRS40 during the Networked and Electronic Media Summit in Barcelona (Serra et al 2010). It is an inertial system based on the detection of strides and readouts from the compass. The user may correct their current position by scanning a $\mathrm{QR}$ code ${ }^{5}$ in specified places.

\section{UTILIZATION OF CARTOGRAPHICAL METHODS AND TECHNOLOGIES}

Analysis of technical literature and white papers published by companies proves that cartographical methodology is still very limited in the process of designing indoor navigation systems. Researchers are working mainly on improving the positioning accuracy, and they often neglect the issue of developing spatial databases and the rules of their effective visualization. The process of designing indoor navigation systems, just like in the case of outdoor navigation systems, consists of a number of tasks that can be supported by the theory and practice of cartography. The most important are:

1. The determination of the model of spatial reference data providing the best description of the position of an object indoors.

2. The definition of a cartographical presentation of spatial reference data.

3. The choice of positioning methods and algorithms to ensure the required quality of spatial location.

4. The design of a clear representation of calculated routes and turn-by-turn directions.

The discussion of these aspects is presented in the following sections of the paper.

\section{The determination of the model of a spatial database for a building}

The creation of plans of buildings is at present the domain of building architects. A conventional architectural-and-construction drawing is prepared based on strictly specified identified standards. In Poland it is, first of all, the PN-70/B-01025

\footnotetext{
${ }^{5}$ 2-dimensional graphical symbol, similar to the bar code.
} 
standard. The visualization methods of a model are strictly determined by the utilization of the final product. In this case, the objective is to prepare documentation for design purposes, as well as information required for the construction of a building. Later, post-completion plans which support the interior design and maintenance of the entire building are produced. For many years, such plans were drawn manually and then plotted with various software packages. CAD (Computer Aided Design) software is a newer approach and recently BIM (Building Information Modeling) class solutions have also appeared. In the case of BIM, not only a drawing is produced, but also a database supporting the whole process of designing, constructing and maintaining the building during its utilization.

At present, such plans developed in various forms and scopes constitute basic spatial reference for indoor navigation applications. In some cases scanned or generated raster images are used directly, being the background for positioning the user (see fig. 1a). In other cases simplified plans of buildings are drawn by graphic designers (see fig. 1b).

a)

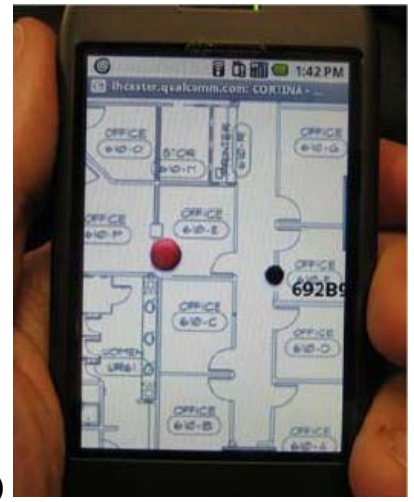

b)

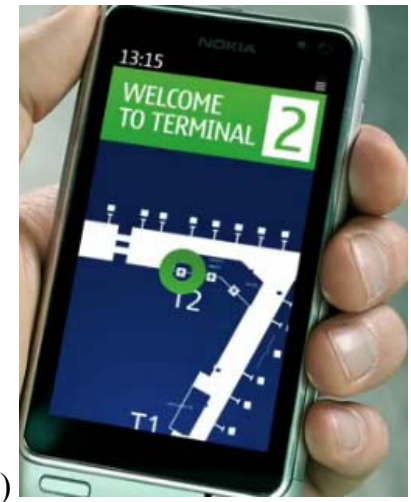

Fig. 1. Examples of maps for indoor navigation: a) scanned or CAD generated image of a construction drawing [1]; b) simplified map of the interior of a building [4]

Utilizing plans of buildings in LBS systems has not been considered in the process of preparing conventional plans. Therefore, introducing changes and developing cartographical models of buildings with the use of GIS methods and theory of cartographical presentations, are required in this field [3].

The following objects may be distinguished in models of indoor spatial databases:

- reference data, which presents the arrangement of rooms, installations and fixed equipment in a building;

- communication routes (typical trajectories of users' movement); 
- movable equipment (such as stands or booth in a commercial center);

- address data (identifiers of rooms, corridors);

- points of Interest (such as locations of automated teller machines, exhibitions);

- marketing data.

The reference data model consists of objects like: walls, rooms and parts of rooms, windows, doors, elements of fixed equipment, infrastructure (installations) or points of orientation. Very important information is conveyed by known locations of access points, such as entrances to buildings or underground parking areas and public transportation stops. Address data is mostly related to the identification of rooms and sectors of the building.

Models of buildings recorded in spatial databases using GIS platforms have been developed for several years. However, in the majority of cases, they were designed mainly for the needs of their utilization in GIS applications. A good example may be the BISDM (Building Interior Space Data Model) developed by ESRI [2], as well as models accessible in Google Maps and presented in November 2011.

It seems that the optimum way is to combine efforts of architects and cartographers in order to develop new standards. Models, databases and drawings made in the process of designing and utilizing buildings could be easily used in the development of indoor navigation systems. Research in this field has been commenced in 2011 at the Laboratory of Mobile Cartography, Faculty of Cartography of the Warsaw University of Technology. The following tasks were defined as a result of the research [3]:

- development of methodological and conceptual foundations for cartographical presentation of indoor maps;

- development of algorithms and data processing technologies for building the GIS database from conventional building projects and post-completion documentation, as well as from BIM (Building Information Modeling);

- research concerning user perception of mobile indoor maps.

The objective of current research is to use the GIS technology to develop a technological path of cartographical model production for buildings. The Laboratory of Mobile Cartography continues to work on the utilization of those models for enhancing the accuracy of positioning systems. At present, new versions of the models are developed that consider the recommendations of OpenGIS ${ }^{\circledR}$ Discussion Paper: Requirements and Space-Event Modeling for Indoor Navigation (Open Geospatial Consortium). 


\section{Cartographical presentation in indoor navigation applications}

The conventional way of presenting indoor maps cannot meet the requirements of navigation applications, since it has not been designed for such purposes (see fig. 2). Using this conventional way in mobile applications may be unreadable for the majority of users and, in general, only a limited range of zooming may be presented.

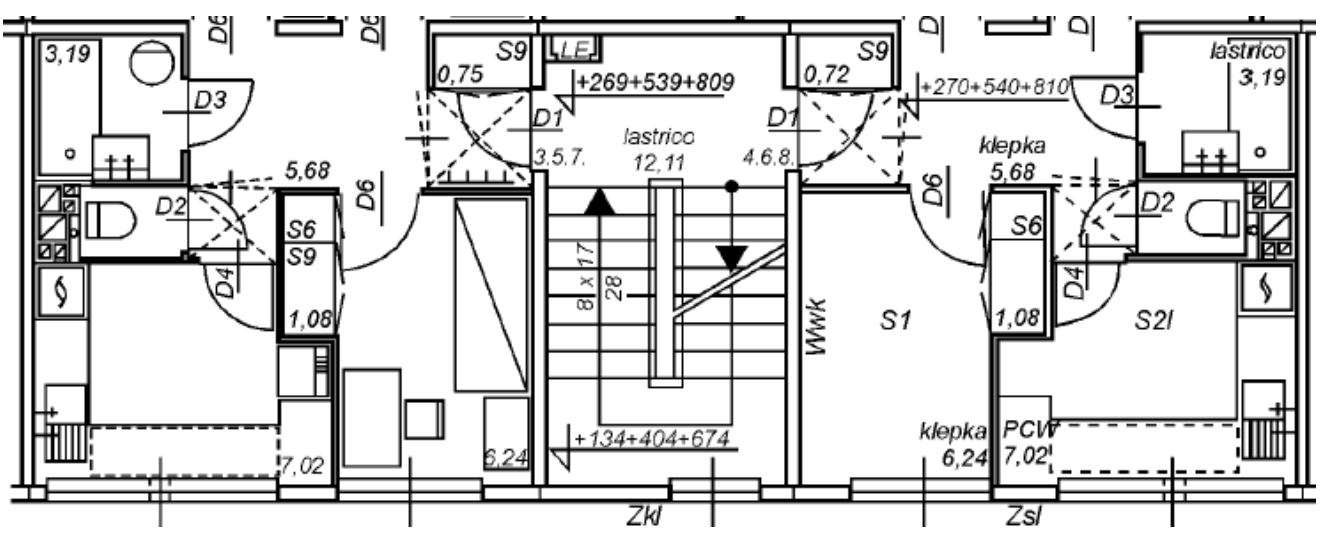

Fig. 2. Conventional construction drawing, following the Polish Standard PN-70 B-01025 [7]

Spatial data in indoor navigation applications should be presented in compliance with the methodology of mobile cartographical presentation. The main concern is related to effective visualization on a small screen of a mobile device, using a wide range of scales, and at the same time ensuring a proper contextual cartographical message.

The methodology of mobile cartographical presentation was discussed in [2]. It is based on the formal definition of a cartographical presentation model, which utilizes the terms of geocomposition, elementary geovisualization and cartographical event. The cartographical presentation model, represented for example by an XML file, may control the entire process of cartographical message in the application.

In order to ensure high quality of cartographical message, it is necessary to develop appropriate standards of geovisualization of indoor maps. Particular attention should be paid to the user's perception of interiors and adjustment of the cartographical message accordingly. The discussed methodology utilizes a series of geocompositions, which consider the mobile application usage context and the type of device.

Cartographical presentation depends directly on the content and the model of the used database. Similarly to car navigation, reference data, address data and the trajectory of the user's movement should be presented. However, in this case, reference data is based on a considerably different data model. Also the nature of the address 
data is different and the specific character of the trajectory is different. In the majority of cases, movement paths cannot be as strictly defined as in the case of car navigation. In many rooms people may walk freely and the rules of indoor movements differ from those which refer to other types of navigation. The issue of geovisualization also covers the issue of correctly presenting the user's trajectory with respect to a relatively high positioning error.

One of the objectives of modern navigation applications defined by many authors is to ensure seamless indoor/outdoor navigation [11]. Therefore, cartographical presentation must also ensure integration of the indoor map with the geographic database of the building surroundings. The user inside the building must have the possibility to see their position with reference to the surrounding area of the building (for example with reference to the entire commercial center with its megastores, parking areas, service facilities, access roads etc.).

Reasonable and user friendly presentation of many floors in a single building is a very difficult and untypical issue in the current cartographical experience. The process is additionally made more complicated by rooms, which vertically exceed levels of particular floors, so-called entresols, internal yards, atria, staircases, connectors or terraces. This opens a variety of issues related not only to $2 \mathrm{D}$, but also to 3D geovisualization. Examples of approaches to the presentation of multi-level interiors may be found in the paper 'A Novel Design for Indoor Maps'[5].

\section{Improvement of the positioning quality using cartographical methods}

In the authors' opinion, a spatial database may be used for the needs of improving the positioning accuracy and calculated routes. The most common algorithms based on the strength of the WiFi signal provide constantly fluctuating coordinates with an error not less than 5 meters. Moreover, the most common algorithms are sensitive to ambient effects such as movement of people [4]. This effect may be observed on Google Maps and in 'Copernicus Science Center Guide'. In the case of Pedestrian Dead Reckoning, the error of the defined position increases with time. In order to preserve accuracy, a common practice is referencing a position originating from other sources of higher accuracy. Such an approach was applied in the prototype pedestrian navigation system, developed at the University of Cagliari [9]. Appropriate utilization of the spatial database allows minimization of positioning errors by adjustment of the user position and determined trajectory to the real arrangement of rooms. 
The lack of consideration of spatial reference data may lead to displaying an object in a different room or in an inaccessible place what, in consequence, makes navigation very difficult and, in extreme cases, confuses users. Based on the information regarding how rooms are used, their geometry and topology, as well as various types of obstacles (fixed and dynamic), it is possible to estimate the quality of the calculated position and adjust the coordinates of a tracked object accordingly. The implementation of this process is based on the assessment of the probability of finding an object in a certain part of a building or room at a given moment in time.

For a system of rooms with well-defined communication routes it is easy to determine a graph which can be used for route calculation. During navigation the position may be projected on the route similarly as in the case of car navigation. More advanced map-matching algorithms analyze the history of users' movements. The trajectory determined from the basic algorithm is then compared with possible paths in the graph [10].

The problem arises when considering 'open spaces'. A graph which represents connections between exits from a specified area does not work, since it is created as a sparse network of connections not corresponding to all possible directions of the users' movement. The significant difference between indoor and car navigation is that the trajectory of a tracked person is not restricted in a similar way to the position of a car on the road. One of the ways to eliminate this problem may be through the introduction of a grid of points in a space, which densifies the graph of connections. In consequence, the geometric quality of determined routes is improved. On the other hand, projection a user's position on such a network does not considerably improve the position. The solution has more drawbacks: preparing the complex graph is a time consuming process and the data volume may cause delays in real time processing on a mobile device.

\section{Methodology of descriptionof indoor routes}

Voice commands generated by the navigation system and geovisualization along with the spatial data model are also elements of the cartographical message. The way of issuing voice commands must be coherent with the graphical message. Although appropriate algorithms are developed and well known for outdoor navigation, in the case of indoor navigation detailed research is required. Radoczky [8] pays attention to several aspects of route description and voice commands for pedestrian navigation. Similar research on the methodology of indoor route description is also performed at the Warsaw University of Technology (the Mobile Cartography Laboratory, the Faculty of Geodesy and Cartography). 
The adequacy of route description highly influences the usefulness of the application and the comfort of its use. A pedestrian looking for a shop in a commercial center or in an airport expects different information message than a driver who travels in the city. In the case of indoor navigation, a general description of the whole route based on floor numbers with reference to selected landmarks is very helpful and sometimes sufficient for reaching the destination. Such description shall be similar to the description that is given by a person asked about a route. A well-constructed description helps to limit the necessity of continuous playing with navigation commands, which may be difficult in real life conditions due to the route complexity level (high freedom in users' movements), relatively low positioning accuracy and the high level of ambient noise. The navigation guidelines shall refer to the characteristic, easy to identify points such as well recognized places and building equipment, lifts, staircases, door numbers, labels, etc.

Particular attention should be paid to the case when the user moves within a small area frequently changing direction, watching an exhibit, stopping by a booth or trying to get past a crowd of people. The voice commands should consider the context of the user. The turning directions should not refer to the position of the body, unless it is clear from the context. Guidelines such as 'take the right turn' may be ambiguous and confusing. An example of description of a simple route for a customer in a shopping mall is presented in table 2 .

Table 2. An example of description of a route in a commercial center (from an underground parking area to the T-Mobile customer service unit) [own study]

\begin{tabular}{|c|c|}
\hline Guidelines & Comments \\
\hline $\begin{array}{l}\text { You are at the level ' }-2 \text { ' of the underground } \\
\text { parking area, your destination is located at level } 3\end{array}$ & $\begin{array}{l}\text { The general description of a route provided before } \\
\text { navigation is started }\end{array}$ \\
\hline Proceed to Exit A & Reference to an easily identified point \\
\hline Take the lift to the $3^{\text {rd }}$ floor & $\begin{array}{l}\text { Explicit guideline, regardless of the direction } \\
\text { of Exit A }\end{array}$ \\
\hline Follow the gallery toward McDonald's Restaurant & $\begin{array}{l}\text { A command avoiding ambiguous reference such } \\
\text { as 'to the right', 'to the left' after leaving the lift }\end{array}$ \\
\hline Turn left behind McDonald's Restaurant & $\begin{array}{l}\text { Here the term 'left' is explicit, due to the known } \\
\text { direction of the user's movement }\end{array}$ \\
\hline $\begin{array}{l}\text { You have reached your destination. The } \\
\text { T-Mobile customer service is to the right }\end{array}$ & The final information \\
\hline
\end{tabular}




\section{THE SCOPE OF UTILIZATION OF CARTOGRAPHICAL METHODS IN TESTED SYSTEMS}

The analysis of available systems (described in Section 2) leads to the conclusion that the scope of utilization of cartographical methods and GIS techniques by their authors is limited.

Google Company released indoor maps of IKEA shops and selected airports in the United States (see fig. 3) in Google Maps 6.0. They are characterized by high cartographical quality, compared to other analyzed applications. An interesting solution is provided for presenting indoor maps of multi-storey buildings. A simplified map is displayed in a defined scale on general geographic background. Successive zooming of the map shows additional elements of the interior, together with a function of switching views of available floors.

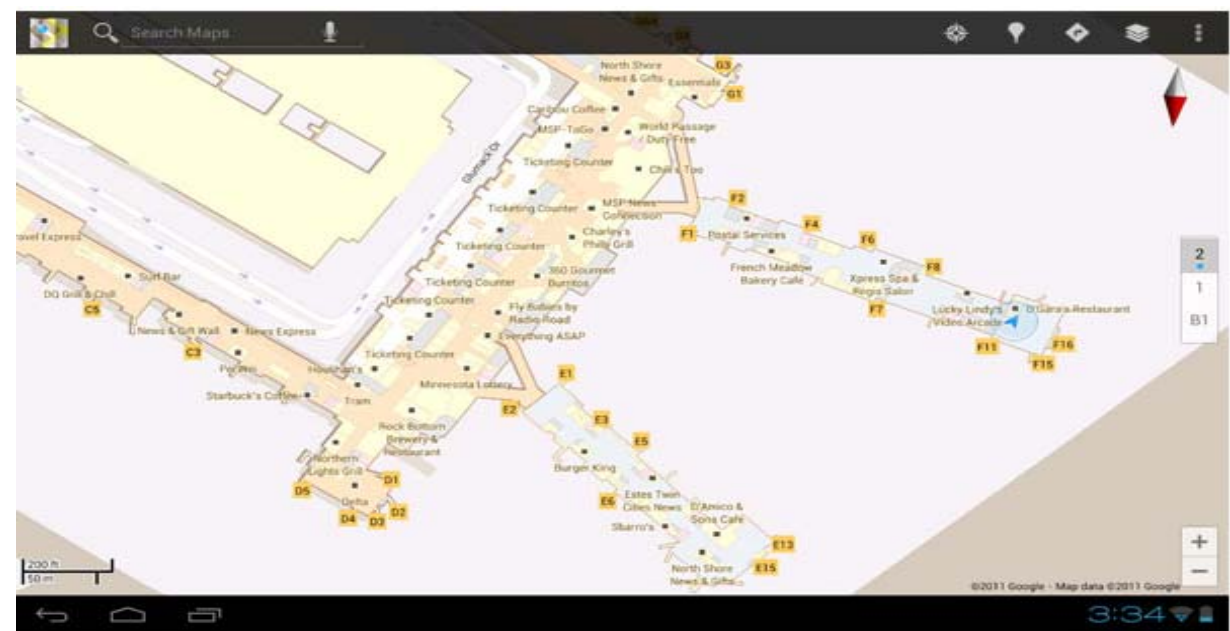

Fig. 3. Indoor map in Google Maps 6.0 [own study]

Based on the analysis of the geocompositions at various scales, the conclusion may be drawn that spatial data is stored in vector format in a typical GIS data model. Such an approach opens possibilities of using spatial data in the process of positioning. However, current algorithms are probably still not dependent on a vector data layer that describes an arrangement of rooms and communication routes. An attempt to calculate a route in Google Maps between two points inside the airport terminal in San Francisco results in projecting the points on the nearest road outside the building. This leads to the conclusion that the current version does not support indoor route calculation. 
In case of navigation in Nokia's system, the position is determined with high accuracy of 30-50 cm, which is sufficient for the implementation of many business scenarios. However, the presentation of the spatial data in Ovi Maps is similar to typical computer graphics not developed by cartographers. The schematic characteristics of the map missing cartographical messages may limit the implementation of some of those scenarios.

MEP solution, presented by the Loctronix Company at MWC $2012^{6}$, is characterized by high positioning accuracy. Real life testing showed that the accuracy close to $1 \mathrm{~m}$ was achieved for typical cases as a result of projecting of the position on the graph of connections between the booths. Untypical tests in less visited parts of the room resulted in positions "projected" on the lines connecting characteristic points of the room. This leads to the conclusion that the current solution considers the topology of the building interior in order to improve the accuracy of the position, but the applied algorithms still require further improvements. In case of this solution, the efforts of Loctronix are focused on the delivery of positioning modules while the aspect related to cartographical visualization of spatial data is within the scope of responsibility of the designers of an application using the MEP component. However, the integration of the building model with the data used in the positioning algorithms remains challenging.

The Samsung Company has also made an attempt to develop and utilize cartographical plans of buildings. The 'Copernicus Science Center Guide' features visualization, which was probably developed based on the GIS database (although they are displayed in a raster format). It should be noticed that they were the first attempts to utilize the imagery of space considering the user's perception indoors. The manufacturer does not specify the system accuracy, but when walking inside the Center it may be estimated as several meters, which is typical for WiFi based algorithms.

Indoor maps developed in accordance with cartographical methodology may play the following roles in the systems mentioned above:

- in the case of systems of high positioning accuracy it improves perception of the map and allows implementation of successive business scenarios;

- in the case of systems of low positioning accuracy it may improve the impression of accuracy in comparison with the position output coming directly from the location module.

\footnotetext{
${ }^{6}$ MWC (Mobile World Congress) — the most important mobile event, taking place in Barcelona every year.
} 


\section{FINAL REMARKS}

In the authors' opinion, the discussed cartographical methods and techniques may considerably enhance indoor navigation systems and accelerate their development. The fundamental knowledge of cartographical methods should be within the interest of designers of these systems. At present the first attempts in this field may be observed, although they are still not mature and complex.

The experience from development of car navigation systems suggests that the importance of spatial data and methods of cartographical visualization have limited meaning only at the first stage of developing such geoinformation products. The positioning itself, even in case of high accuracy algorithms, cannot meet the expectations of the majority of users. Since we are dealing with users who are aware and well educated in using navigation systems, which became popular these days (in particular car navigation systems), manufacturers of indoor navigation applications will need to consider the discussed cartographical aspects much faster than in the case of car navigation.

\section{REFERENCES}

[1] Giorgetti G., Farley R., Chikkappa K., Ellis J., Kaleas T., Cortina: Collaborative Indoor Positioning Using Low-Power Sensor Networks, International Conference on Indoor Positioning and Indoor Navigation, Guimarăes, Portugal, 2011 .

[2] Gotlib D., Methodology of cartographic presentation in mobile positioning and navigation systems (in Polish), Prace Naukowe Politechniki Warszawskiej, Geodezja, 2011, No. 48.

[3] Gotlib D., Development of cartographic presentation methods in mobile systems, including indoor positioning systems (in Polish), the report on the work of the Department of Cartography, Wydział Geodezji i Kartografii, Politechnika Warszawska, 2011.

[4] Mautz R., Overview of Current Indoor Positioning Systems, Geodesy and Cartography, 2009, 35(1), pp. 18-22.

[5] Nossum A. S., IndoorTubes A Novel Design for Indoor Maps, Cartography and Geographic Information Science, 2011, 38(2), pp. 193-201.

[6] OGC, OpenGIS ${ }^{\circledR}$ Discussion Paper: Requirements and Space-Event Modeling for Indoor Navigation, Open Geospatial Consortium, 2010-12-11. 
[7] PKN, Polish Standard PN-70 B-01025, Graphic symbols on architectural and construction drawings (in Polish), Polski Komitet Normalizacyjny, 2004.

[8] Radoczky V., How to design a pedestrian navigation system for indoor and outdoor environments, Location Based Services and TeleCartography, 2007, Springer, pp 301-31.

[9] Serra A., Dessì T., Carboni D., Popescu V., Atzori L., Inertial Navigation Systems for User - Centric Indoor Applications, Networked and Electronic Media Summit, Barcelona 2010.

[10] Spassov I., Algorithms for Map-Aided Autonomous Indoor Pedestrian Positioning and Navigation, Doctoral Dissertation, EPFL Lausanne, 2007.

[11] Virtanen A., Koskinen S., Towards Seamless Navigation, Proceedings of the Mobile Venue '04, Athens 2004,

http://virtual.vtt.fi/virtual/noppa/mvenue/towards\%20seamless\%20navigation.pdf.

\section{Websites}

Bev-Al Communications, Loctronix Demonstrates Latest Indoor Positioning Technology at Mobile World Congress, 28th of March 2012, http://www.geoplace.com/ ME2/dirmod. asp?sid=\&nm=\&type=MultiPublishing \&mod=PublishingTitles\&mid=13B2F0D0AFA04 476A2ACC02ED28A405F\&tier=4\&id=C690BA7F76E44B4B8D3136A70C0875A8

ESRI (2011), http://support.esri.com/en/downloads/datamodel/detail/44.

Merritt R., Nokia tweaks Bluetooth for indoor navigation", $29^{\text {th }}$ of November 2011, http://www.eetimes.com/electronics-news/4230993/Nokia-tweaks-Bluetooth-forindoor-navigation

Nokia (2011), http://www.gsmarena.com/nokia_indoor_positioning_promoted_on_video_ looks_seriously_cool-news-2525.php

Volpe J., Google Maps 6.0 hits Android, adds indoor navigation for retail and transit, $29^{\text {th }}$ of November 2011, http://www.engadget.com/2011/11/29/google-maps6-0-hits-android-adds-indoor-navigation-for-retail/.

Received April 2012

Reviewed October 2012 